\title{
Cosmic Relationships \\ Comets, Human Behavior and New Discoveries on Easter Island
}

\section{Candace Gossen, Ph.D., LAc., Ronin Institute, candace.gossen@ronininstitute.org}

A train is like a comet! Its enormous presence can be felt long before it is heard. The awareness of a distant rumbling begins with a feeling spreading across the earth beneath your feet. Then the cyclic churning reaches the ears as a beastly rhythm of breath. All of this intense energy catching up with itself speeds past, slicing through a temporal timeline that is quite intent on maintaining what it is until acted upon. A comet is that train that comes speeding through on its invisible track, wobbling and spitting along its path and yet part of and separate from the synchronicity that maintains the rhythms of the planet. I watched this moment today while sitting in a narrow ancient gorge on the Columbia River that was formed by glaciers thousands of years ago. A place in time where endemic flowers still bloom on its sheer walls. Certainly the periodic interruptions of these powerful entities churn and energize this space along its way, just as comets disrupt and change the universe.

Comets, asks Carl Sagan, "What are these graceful visitors to our skies? We now know that they bring both life and death and teach us about our origins." (Sagan, 1997)

The thought of comets first entered my thinking quite auspiciously before I knew we humans on Earth would be graced by 3 passersby in 2013 and seemingly more cosmic events ever since. It was on my long drive from Portland to Santa Fe that I felt the enigmatic presence of my speeding truck through ancient landforms of rock cliffs, giant and old trees growing for more than 4,000 years. I was in motion like a comet slicing through distant places and time.

Within that capsule of my moving truck was something even faster, my thoughts. They were focusing on Rapa Nui (Easter Island) and the patterns I had noted in the lake sediment cores from Rano Kao. I was looking at patterns, periodicity of drought, depleted and enriched isotopes, variations and intervals of 600 and 700 years respectively. I thought further on the global events that the lake had captured in its sediments, so far away and isolated in the Pacific Ocean, but yet watching. In the 9 meters of lake sediment cores, there were 7 major events coinciding with tephra, depletion of O18, cold temperatures and major cultural events recorded around the world. Without written records this long ago, we can only speculate on our ancient humans and how solar eclipses, comets and celestial events affected their lives.

The cores accuracy reported dates of the Last Glacial Maximum, Younger Dryas and the eventual extreme hot period that began at 9,275BP. For nearly 5,000 years following things were very dry with little rain but Rapa Nui maintained a diversity of 17 species of 
trees as part of a sub-tropical palm forest offering 40 species of native plants living under its canopy. Punctuated events including a 9,225BP episode began a 637 year cyclic extreme cold event. In 4,170BP, the noted 4.2K Event around the world, saw the lake Rano Kao completely desiccated. The one that most of us are interested in now is the 545BP event during what we call the Little Ice Age, a time period where things turned colder bringing drought and floods all over the world. It was then also, 545 years ago the last pollen of the giant palm forests of Easter Island disappeared. (Gossen, 2011)

Coincidentally or not, a comet ushered in the last resignation of Pope Gregory in 1415AD amid a civil war in the Roman Catholic Church known as the Great Western Schism, and nearly 600 years later another pope retired in early 2013 under the skies of 3 comets in our solar system. Cycles and comets, particularly Halley's can be timely connected with political unrest, hierarchy dissolution, warfare, disease, creations of kingdoms and great cities, disappearance of giant trees and notable human behavior based on fear of life and death that bring great change to humanity and planet Earth.

As the bringers of life and death, I began to note actual historical events with the sightings of 1P/Halley, otherwise known as Halley's comet so named after Sir Edmond Halley in 1705 , but what is this comet exactly besides a speeding ball of fire, gas and carriers of starstuff?

Halley's is a retrograde comet, orbiting opposite of our sun's planets, having a vast coma with a nucleus approximately $8 \mathrm{~km}$ x $8 \mathrm{~km}$ x $15 \mathrm{~km}$ long. (Sagdeev, 1988). The structure of this comet has been referred to as a rubble pile in movement containing $80 \%$ water vapor, $17 \%$ carbon monoxide and 3-4\% carbon dioxide. Trace gases include hydrocarbons, methane and ammonia. The dust particles left behind are composed of carbon-hydrogenoxygen-nitrogen compounds which are the alchemy of the outer solar system along with silicates picked up along the way from terrestrial rocks. (Sagan, 1987)

Harmless as it seems describing a comet in a benign scientific way of water and rock, I turned to the energy that was trailing the comets. Just like the speeding train, the virtual slicing was leaving residue and affecting everything on earth, schisms of punctuated equilibrium shaking up things each time it graced its way along our path.

Now intensely curious as to the 76 year cycle of Halley's being documented for thousands of years along with omens of political collapse, religious hierarchal change and huge natural shifts I began to uncover others that had written about these coincidences.

The first historical documentation found was 2481 years ago (468BCE) noted by Pliny the Elder as a meteorite that landed in the forests of Thrace, written in the book by Donald Yeomans, Comets: A Chronological History of Observation, Science, Myth, and Folklore in 1991. 
Reaching back into the Chinese Shiji, otherwise known as the Records of the Grand Historian: Basic annals of the First Emperor of Qin, Chinese astronomers from Sima Qian's Shiji (c. 109BC-91BC) wrote “In the 7th year of Emperor Qin Shihuang of the Warring States, a broom star first appeared in the east, then it appeared in the north." (Pankenier, p.507)

In ever greater detail Edwin Emerson wrote a book in 1910 called Comet Lore: Halley's Comet in History and Astronomy, which sold by Schilling Press in New York for only 50 cents. The more he uncovered these coincidences he managed to detail them by categories of war, earthquakes, great historical events and memorable people since Jesus.

Ironically the year his book was printed was also one of mass hysteria where people feared the ending of the world with a coming comet that would bring with it a toxic gas called cyanogen.

The deeper I searched for energy I discovered the chemistry. A unique but unknown hitchhiker of the comet's visit is cyanogen. It is is a neurotoxin and in short term causes stress disorders. Cyanogen $(\mathrm{CN})_{2}$ is a colorless, toxic gas with a pungent odor. The nitrogen is bound to the carbon atoms (NCCN) and reduces to cyanide, a poisonous gas. which has a bluish-violet color and this is what the astronomers saw in the spectroscopic analysis in 1910. During this time cyanogen was also found to be important to the newly created fertilizer industry and is still used in production today. However the side affect to breathing creatures in close proximity is irritation to the lungs, headache, dizziness, increased rapid heartbeat, nausea, loss of consciousness and death depending on density and length of exposure to the gas. (Muir, 1971).

In 1910, Halley's comet was due for a return, and this time with new astronomical equipment allowing a better view of its approach, the astronomers saw a massive cloud of gas including cyanogen trailing the comet and immediately widespread panic drove people into barricading themselves into their homes with comet pills to stave off the poisonous gas. The comet came and went as did the hysteria that came with it. Some however would say it ushered in the beginnings of World War I that followed soon thereafter.

Certainly fear itself does not need a gas to provoke its response, just the presence of this fireball in the sky brings change. When cyanogen is burned in oxygen it emits one of the strongest hottest natural flames. (Muir, 1971) When the comet comes near to the Earth and makes it cyclic roundabout, heading back out into space away from us and back towards the sun, it puts the "metal to the pedal" and for several months has been seen expelling a cloud of starstuff including cyanogen. In 1910, people had good cause to be interested, as the comet was only 0.15 AU (23 million kilometers) from Earth. (Yeomans, 1998). 
Halley's orbit is elliptical and retrograde. Throughout the hundreds of thousands of years it also has varied in how close it passes to Earth. The closest recorded passing in our known historical timeline of sightings was in 837AD where it was $0.03 \mathrm{AU}$ away, which equals to 4,487,936 $\mathrm{km}$ between the comet and Earth. All around the world even the most remote people have noted this particular comet.

Why, however do these comets bring such change? All we know is the history we reflect back upon. Why is there such disruption at these apparent timings? Does the mere fact of seeing a celestial object in motion, such as the train's enormous presence insight enough fear that is contagious amongst humans? Or is there an energy, a chemistry found in the patterns of climate change coincidentally aligning with these events.

For thousands of years humans have documented similar events, as fireballs etched into petroglyphs in the desert southwest, in old Mayan ruins and on the wood rongorongo tablets of Rapa Nui. At Chaco Canyon, deep into the desert gorge some eight miles away from the famous solar marker on Fajada Butte are the isolated petroglyphs at least 20 feet above ground of a star, a broom star and handprint as a signature of testament of a comet and perhaps the supernova of 1054 and Halley's comet of 1066AD. (Malville, 2008)

In 1066AD as the Pueblo People were etching their sightings on the walls, a great battle in Europe was ensuing. While the Normans were invading England, Eilmer, an astrologer and monk at the Abbey of Mailmesbury wrote of the fall of the heirarchy calling the comet the bringer of tears, death and evil. His writings became part of the History of the English Kings, the Gesta regum Anglorum carried on by historian William of Malmesbury. Shortly thereafter, the great solar ceremonial center of Chaco Canyon, Chimney Rock and Mesa Verde were also in an ultimate hierarchal decentralizing of these large ceremonial centers.

Other comet sightings include 1222AD when Ghengis Khan invaded Europe, and 1456AD when the Ottomans invaded the Kingdom of Hungary but in response the Christians delayed the takeover for yet another comet sighting some $70+$ years later.

This year of 1456AD is also auspicious to my own findings in the lake sediments of Rano Kao on Easter Island. A 115 year extreme cold event began in 1390AD and peaked in 1456AD. During this time of dormancy for the giant palms, and perhaps a very difficult environment for the islanders to contend with, Halley's comet reappeared. Could this broom star, which would have appeared high in the sky with its tail arcing downward to the east be the red star they named Pau on their rongorongo scripts? Sergei Rjabchikov wrote in the Rapa Nui Journal of 1999, about the mysterious star Pau being the "key to the Washington tablet.” He quoted Metraux (1940:53) “...Pau, a star which appears in October or November. The appearance of these three stars in October foretold death and evil....Pau was sometimes bad and sometimes good." In Rapanui language Pau means "bright, crimson, red" which becomes white, pale and clean as it is written by Barthel as 
a place name Hero mapa pau

Seventy-six years later, Halley's comet returns in 1531 to shed light onto a period in which the moai no longer held their mana, and all creation of these stone statues ceased. Could the presence of comets, supernovas, eclipses and global cultural shifts be a mere coincidence? Cause and Effect may never be known, however we can overlay facts and data together and begin to see the connections. (Figure 1)

Method:

In 2005, 2008 and 2014 I cored the crater lakes of Rapa Nui in search for answers of what happened to the trees. Challenging the theory that humans had cut them all down to move the moai around the island. I wanted to know if something else like a climate event, or disease, or some ecological other was responsible for 16 million of the planet's largest palm trees to disappear. It's a very plausible idea that humans could have cut them all down since we see deforestation all around the world. Through excavation data and previous pollen cores from Rano Kao, John Flenley, mathematically calculated that from the first signs of charcoal to the last palm pollen observed in the samples, showed years of cutting and burning that estimated 55 palms trees, standing 2-3 meters in diameter and 20-30 meters tall, would have been cut daily and continuously for 800 years to reach the 16 million estimation given by the work of Meith and Bork (2003).

Taking an unbiased approach using scientific method my work covered 15,000 years of plants and trees building upon the first palynological study of the lakes by John Flenley in the 1980s. The KAO3 core from 2005 was taken 450 meters from the edge of the lake Rano Kao, which is very near to center of a $1 \mathrm{~km}$ rim to rim volcanic crater, the remains of an ancient volcano formed over one million years ago. Throughout the years the lake has witnessed intense climate events, many different types of trees and those that survived until most recent days. Currently the lake has a floating mat, one of a few in the world that was formed when the Tavari (Polygonum acuminatum) and Totora (Schoenoplectus californicus) grew across a desiccated lake in 3,500BP. The thousands of years that followed brought more rain than evaporation and the water began to uproot these tangled and twisted plant roots until the pressure forced its freedom to float on the surface of the lake. There is a 2-4 meter mat of living plants that hold the last 1,000 years of climate, plant and human history. Below this mat is 12.5 meters of dark oxygen less water where things slowly decay, eternally resting into the lake sediments, including the fossil pollen that land on the water's surface from near and far.

These aquatic plants growing on Rano Kao were useful in the first oxygen isotope analysis of this lake. Being full of tannins from the plants, there weren't any calcium 
carbonates including diatoms which are generally useful for these types of studies. Teaming with Brent Wolfe and his grad students at Wilfrid Laurier University, sediment samples were used for the lake water oxygen isotope analysis. Reconstructing a rainfall and drought profile over the last 15,000 years is what graph (Figure 2) is composed of. You will note 8 significant events where such extreme depletions and enrichments of $\mathrm{O}^{18}$ would have changed the ecology of the island in drastic ways. Alongside these events I sampled the sediments for all non-pollen palynomorphs as ecological descriptives to help determine drought and rainfall cycles on the island. What came of all this data is noted as an average 637 year depletion cycle where the island turned cold and sometimes very dry where rainfall was scarce. In opposition when $\mathrm{O}^{18}$ peaked we see support for hot humid to extreme hot-dry events every 719 years. Current trends in the lake show that it is increasingly evaporating with warmer temperatures, however the long term trend over the last 9,250 years show a cooling trend, a response much like what others have found in the trends of Lake Titicaca (personal conversation, Dunbar et al).

In certain events tephra was found in the samples and could be traced to volcanic activity near the Pacific ocean of a VEI 5+ event. Certainly with over 70 pyroclastic cones visible on the surface of the island local events were also active in the very recent past.

The history of the island and the memory of the giant palms have been lost due to unfortunate human circumstances of slave stealing that killed more than a thousand of the last surviving Rapa Nui people including the last King and the holders of the oral knowledge of their culture. There are 2 petroglyphs carved into rock noted by Georgia Lee, and less than 5 symbols noted in the rongo rongo tablets which show a palm tree or likeness. There is no Rapa Nui name for these palms. The Sophora toromiro however is a native tree that shows early existence in 15,000BP with the last wild tree found in 1960. The folk lore states that a sacred tree would have been planted next to an ahu, ceremonial platform, and then called Toromiro regardless of its species. To the Rapa Nui people, a tree and the ceremonial platforms, ahus, were both sacred before the Moai were placed upon them.

William Liller, an astronomer with the Institute Isaac Newton in Santiago Chile, conducted extensive studies during the 1980s and 90s on the alignments of the more than 300 Ahus found on the island. Mulloy in 1965 systematically measured the coastal ahus for celestial orientations and found that out of the 226 ahu measured, only 45 had possible significant alignments and these were marking a true (astronomical) north or east-west axis. Mulloy never published these records and Liller picked off where he had laid down the investigation with looking inward to the non-coastal moai. Liller found that more than $25 \%$ of the remaining ahu did align with a solstice, equinox or celestial event. His conclusions were that the inland ahus were important for agricultural reasons in marking the beginning of seasons. (Liller, 1993) 
During my fieldwork in 2014 I had been aware that 3 comets had come and had been witnessed on the island, and I would be present for the Autumnal Equinox in March. I went to the Timekeeper, the noted solar observatory Ahu Huri A Urenga. This ahu is situated between Puna Pao (the red scoria quarry used for the topknots of the moai) and Maunga Orito (the obsidian quarry), both of which are three kilometers from the modern town of Hangaroa. Huri A Urenga has a large ceremonial platform with a single moai on a twisted platform at 20 degrees from the perpendicular walls. Mulloy and Liller both noted a direct alignment to the June (winter) solstice sun. Another confirmation of Mauna Mataengo ("Mount Tear-stained Eye") lay on a line pointing precisely in the same direction for sunrise, and a nearby point on another hill marked the setting sun. Outside the wall of the ceremonial platform, 5 pairs of cupules lay under the grass that aligned to three solar significant rising points and true north.

In the timeline of architectural construction on the island, the ahus came first. It was latter in time that the moai were created and placed upon them changing the ceremonial ahus to ancient elder worship. Huri A. Urenga is unique in that he is the only moai with two sets of hands. I have heard the speculation made that the carvers made a mistake on the first set of hands and rather than rebuild the moai, they carved out a second set of hands. Given the highly skilled moai builders and the great effort to move these moai to their places, I began searching for the significance and meaning of two hands. During the morning of the Equinox, I watched the Southern Cross due south from the platform walls and the moai. As the sun began to rise it cleared a small hill and speckled light shifted through the now grove of trees blocking the connection between sunrise and Huri. In the past these trees would have been cleared and the sunrise would have began at the foot of the platform and slowly creeping upward towards the face of Huri. Solar noon would have circled above his head and moved toward sunset upon his back. Huri's hands may indicate the movement of two seasons, both equinoxes both Fall and Spring, perhaps it is both male and female spirit. Huri A. Urenga as noted by Liller is also a significant in land winter solstice marker.

The significance of this unique solar marker has long been forgotten, as Huri A Urenga was laid down long ago until its resurrection in 1972. Names, just like places were lost and the folding in of this name is only a place marker today. However, looking back into meaning the Rapa Nui "A" means possession. There are only a few ahus that use this significant meaning, another is Ahu Moai A Mata Mea which means "belonging to the red (evil) eye," and "is the moai that belongs to the planet Mars "(Liller p.23). For Huri A Urenga, Huri means "change" in Maori, with A meaning "possession or belonging to" and separating Ure Nga which is proper in the current language. In Maori the Kai Ure is the charm of healing from numerous ills, and Nga is the "upward motion." Huri A Urenga may have been the Timekeeper of the island, the place to reset time each season, to direct and find true north for celestial navigation, and to atone for ones sins and ask for healing for illnesses from the stars. 
The cosmic sky was very alive during the time of the ancient Rapa Nui, and they have noted in the rongo rongo a Red Star called "Pau." According to tradition, the astronomerpriests preserved the vital information of the stars, sun, moon, season changes and cosmic activity in oral expression as well as marked in the cupules, platforms, tablets and statues. Periodically the astronomers would climb the tupa (towers) to announce the changing positions of the stars for safe navigation and daily life. The red star Pau grouped with Matamea (Mars) and Tautoru were noted to be harbingers of trouble and danger. These were also cyclic and the knowledge of their appearance and return were critical. Matamea's return to the sky occurred every 780 days. Pau has been drawn onto the rongo rongo script as noted by Rjabchikov (1999). Pau may have been the returning Halley's comet, or the brightest star in the Earth's sky, Sirius with a noticeable red shift, was the first star to have its velocity measured in 1968 by Sir William Huggins. During the heliacal rising of Sirius, namely the day it becomes visible just before sunrise after moving far enough away from the glare of the Sun, would have been in the shadow of the sun for 70 days. Its reappearance is noted in ancient Egypt to occur just before the annual flooding of the Nile and the summer solstice, which would have been the winter solstice for Rapa Nui. Due to its declination of roughly $-17^{\circ}$, Sirius is a circumpolar star from latitudes south of $73^{\circ} \mathrm{S}$. From the Southern Hemisphere in early July, Sirius can be seen in both the evening where it sets after the Sun, and in the morning where it rises before the Sun.The season following the star's heliacal rising (i.e. rising with the Sun) came to be known as the Dog Days of summer, bringing many places drought. Perhaps, the two sets of Huri's hands were the setting and rising of Sirius, and perhaps Ahu Huri A Ure Nga, "the moai that belongs to the healing star" could have been the most significant place on the island at one time.

In Rapa Nui folklore the celestial bodies and events were just as important as rainfall. When Jacob Roggeveen landed in 1722 their observations were that the Rapa Nui people "had prostrated themselves towards the rising sun." (Liller 2003) They planted their food crops by phase of the moon, feared omens like Mars appearance in the sky, sought help for ailments, marked their daily calendars for ceremonies and events, and began their year shortly after Pleiades first appeared in the morning sky - or when the sun "rose farthest to the north." (Liller) Katherine Routledge, during her year long stay on the island in 1914 wrote about the significance of the story of Orion: "A certain married woman, on going down to bathe was carried off by a stranger. When her husband discovered this, he slew her in anger, and she fled up to be a star. The husband then took their two boys, one in each hand, and followed her to the sky where the three form the belt of Orion. The wife, however, would have nothing to do with them and remained in a separate pat of the heavens."

These three stars, which rotate about the east and west points of the horizon were important for navigation as well as in the anticipation of Sirius. It is Pleiades, named Matariki in Rapa Nui, meaning "Eye of the King" whose first appearance in the early morning sky would mark the beginning of the new year. 
During the AD700s the night sky became very alive with comets and eclipses. Halley's comet arrived in 760AD and then was followed with 5 major eclipses beginning in 762-772AD. This unusual activity could have brought upheaval on the island as all were watching. It is during this latter period that we first find significant charcoal in the sediment cores marking the beginning of the industrious time of the moai building. Over in North America the time period of 750AD the Late Woodland shifted to the Emergent Mississippian.

In 837AD Halleys returned soon after a solar eclipse and this time it was closer than all recordings in history of its passing. The ancient Rapa Nui would have seen a "broom star" as the Chinese have called it nearly directly overhead with a comet tail reaching 90degrees towards the horizon. In 880-900AD a great drought took hold of the world and then Halleys returned in 912AD.

In the journals of the Voyage of Discovery, 1,000 years later, Captain James Cook stated "...the Polynesians distinguish stars separately by name and know in what part of the heavens they will appear in any of the months during which they are visible in their horizon; they also know the time of their annual appearing and disappearing with more precisions than will easily be believed by a European astronomer."

When the Rapa Nui were watching the skies intently during these active times, others around the world were doing the same and seemed to be inspired to erect temples, ceremonial platforms, celestial markers and sacred spaces to watch the stars above. In the Desert Southwest, the ancient pueblo dwellers began building towers and kivas. The culture produced specific identifying black and white geometric patterned pottery and etched solar markers into the rock nearby. The cosmic sky increased its activity and in 1006AD a supernova exploded and was marked around the world. In 1018 the Northern Luna Standstill was captured at Chimney Rock and on Rapa Nui a huge amount of charcoal was found in the sediment cores of Rano Kao.

Between 1000 and $1100 \mathrm{AD}$ there were noted 241 solar eclipses and 246 lunar eclipses that would have been seen. Particularly in 1054AD a supernova became what is known as the Crab Nebula and it was marked high upon the walls near Pueblo Blanco at Chaco Canyon along with a broom star, a sign that they too were watching the cycles of the famous comet Halleys. Solar Architecture increased at Chaco Canyon, Hovenweep, Chimney Rock and Mesa Verde, while moai building on Rapa Nui became increasingly larger. Everything was intensifying. In 1050AD the Mississippian tradition exploded across the landscape and began building Woodhenges as solar ceremonial centers in Cahokia (Iseminger, 2010). These henges, built of red cedar continued into 1200AD.

In 1064AD Sunset Crater erupted in what is now Flagstaff, Arizona disrupting the Anasazi and pueblo dwellers. Halleys returned in 1066AD while European world was 
collapsing in the Battle of Hastings, meanwhile in 1076AD the great kivas of Chimney Rock were in full ceremony. In 1090AD another great drought set in which perhaps pushed Chaco Canyon to build the Great House 1093AD. In 1133AD a solar eclipse was noted and 1170AD Mars, known as Matamea stood in front of Jupiter and made quite a show, and then Sunset Crater erupted again in the desert southwest. Meanwhile in the time of the Classic Maya the hierarchy was breaking apart.

By the time of 1150AD great change was happening, people were moving into cliff dwellings at Mesa Verde, Chimney Rock had been abandoned, Chaco Canyon ceased to be a solar ceremonial center, the Classic Maya had already shifted into small bands, the ancient Anasazi were moving to the San Pedro river in small groups and on Rapa Nui the change was coming. Drastically altering the landscape in $1173 \mathrm{AD}$, the charcoal record had a high incidence of charcoal which signified alot of burning, although the isotopes in the lake show a similar environment to our current rainfall and evaporation rates.

For the next sixty years on Rapa Nui however, a long term drought peaked in 1230AD with an extreme hot event lasting 10-20 years. This is the time period we believe we have uncovered a water fertility site at Ava Ranga Uka, a collapsed lava tube in the middle of the island of Rapa Nui. A place where during rainfall periods had great waterfalls and pools, and in drought one of the few places where water finds its way from both sides of the island down into this 8 kilometer creek to the sea. Down into what appears to be a ravine, is a multi-layered plaza under a single moai called Ahu Henua Nua Mea. This moai, perhaps the most inland found ahu, is directed towards the north, perhaps toward the moon as it is she who is associated with fertility in humans, animals and plants of many cultures. Down below in the excavation are palm planting pits nearly $80 \mathrm{~cm}$ in diameter. With a growth rate of $1 \mathrm{~cm}$ per year, the ancient palms would have been nearing their first flowering session that takes nearly 100 years. These deliberate plantings may be some of the last standing palms in an attempt to save them, or use them in some reverence for this water site.

The Great Towers at Mesa Verde were erected during this time and around 1222AD Halleys made its reappearance. The Drought Panel at Fremont Indian State Park, the ancient village at Clear Creek Canyon, depicts a whole story on crumbling rock pillars about a great drought during this time period and the inward journey to the pit houses.

By the time 1300AD came about, most of these cultures were disbanding and abandoning the large ceremonial centers. In 1350AD in the cores at Rano Kao, the isotope record drops drastically which signifies a very cold event occurred, then shifting drastically to high evaporation within 40 years. It is this event beginning in 1390AD lasting 115 years that is the longest and most extreme cold event recorded in the lake sediments. By 1405 the fossil pollen had decreased drastically, and by 1456AD the giant palm trees were dormant. The nemesis for these trees is cold, they are full of sugar water with a vascular system liken to animals. These giant palms in their dormant mode began to die and did 
not produce new seed. this was the year Halleys returned into view. Even in Peru, Pachcuti expanded outward. In 1460AD a comet came to visit and brought with it a harbinger that would collapse most of these ancient cultures into small bands in search of water and shelter.

The isotope record of Rano Kao rainfall oscillates around a current normal over the last 2,000s except for these drastic punctuated events, the last cold event peaking in 1456AD. (Figure 3). The periodic intervals between these cold events has been measured to occur every 637 years. Moving the calculation forward, the next expected peak would be 2027AD and may have already begun as my recent measurements of the lake water show two meters less with less evaporation than six years earlier.

Comets, eclipses, lunar standstills, supernovas are all markers of cosmic events that we can see mirrored and reflected in the artifacts left behind in many cultures. My own work has found similarities amongst the Anasazi, Mayan and RapaNui. Perhaps these coincidences are due to geographic location within 30degree North and South of the Equator relatively close in longitude and affected similarly by global climate events driven perhaps alongside these cosmic events. Observation shows that civilization has always watched the skies, and depended greatly on how climate shifted at the appearance or absence of certain stars. These cultures that I have observed including the Rapa Nui, the Anasazi, The Mississippian and Mayan for instance noted, marked and left behind great markers of these events if only we can pieces these patterns together. Matching these times periods with climate data collected from the lake sediments shines a new relationship between what was happening in the sky and how it affected earth and perhaps affected the stars in return. Ancient medicine from the gifts of Paracelsus, the Bon and nomads of the Asian Plateaus, the Dogon in Africa talk about the effects of stars on people, and how our perception of them is just a reflection of the workings within our own bodies. The microcosm becomes the macro and visa versa.

Having just turned into a new calendar year 2021, we have found humanity in a pandemic, unexpected, but marked once again with a Christmas Star, where a conjunction between Saturn and Jupiter brightened the stars, bringing us all out into the night sky, to think about the last time this view happened was nearly 800 years ago, and does this now mark us into the history of global change?

\section{References:}

Bork, H. and Mieth, A. (2003) The Key Role of Jubaea Palm Trees in the History of Rapa Nui: A Provocative Interpretation. Rapa Nui Journal, 17 (2). 
Chyba, C. and Sagan, C. (1987). "Infrared emission by organic grains in the coma of comet Halley". Nature 330 (6146): 350-353.

Dunbar, et al Stanford University. (2001, January 29). Lake Titicaca Study Sheds New Light On Global Climate Change. ScienceDaily. Retrieved January 16, 2021 from www.sciencedaily.com/releases/2001/01/010129064113.htm

Emerson, E. (1910) Comet Lore: Halley's Comet in History and Astronomy. The Schilling Press. NYC, NY.

Flenley, J.R. and S. M. King (1984) Late quaternary pollen records from Easter Island. Nature 307: 47-50

Flenley, John and P. Bahn (2003) Enigmas of Easter Island. Oxford University Press, Oxford.

Gay-Lussac, J. L. (1815). "Recherches sur l'acide prussique". Annales de Chimie 95: $136-231$.

Gossen, C. (2011) Deforestation, Drought and Humans: New Discoveries of the Late Quaternary Paleoenvironment of Rapa Nui (Easter Island) ProQuest, 485 pages; 3469133.

Liller,William (1993). The Ancient solar Observatories of Rapa Nui: The Archaeoastronomy of Easter Island. The Easter Island Foundation.

Malville, J. McKim. (2008) Guide to Prehistoric Astronomy in the Southwest. Johnson Books, Boulder.

Mucciarone, D. and R. Dunbar (2003) Stable isotope record of El Nino - Southern Oscillation events from Easter Island. In J. Loret \& J.T. Tanacredi (eds). Easter Island: Scientific Exploration into the World's Environmental Problems in Microcosm: 113-132.

Muir, G. D., ed. (1971). Hazards in the Chemical Laboratory. London: The Royal Institute of Chemistry.

Pankenier, David W.. "Cosmology and the Calendar", Astrology and Cosmology in Early China. $1^{\text {st }}$ ed. Cambridge: Cambridge University Press, 2013. pp. 242-258. Cambridge Books Online. Web. 14 February 2016. http://dx.doi.org/10.1017/ CBO9781139017466.014

Rjabchikov, S.V., 1999. Astronomy and Rongorongo. Rapa Nui Journal, 13: 18-9. 
Sagdeev, R. Z. Elyasberg, P. E. Moroz. V. I. (1988). "Is the nucleus of Comet Halley a low density body?". Nature 331 (6153): 240-242.

Sagan, Carl. (1997) Comet, Ann Druyan coauthor, Ballantine Books, 1985, ISBN $0-345-41222-2,496$ pgs.

Yeomans, D. (1991) book Comets: A Chronological History of Observation, Science, Myth, and Folklore.

D. K. Yeomans (1998). Great Comets in History. Jet Propulsion Laboratory. Retrieved 15 March 2007

Wolfe, Brent and K. Beuning (2001) Carbon and Oxygen Isotope Analysis of lake Sediment Cellulose: Methods and Applications. W.M.Last \& J.P. Smol (eds) 2001. Tracking Environmental Change Using Lake Sediments. Volume 2: Physical and Geo chemical Methods, p. 373-400. Kluwer Academic Publishers, Dordrecht, The Netherlands.

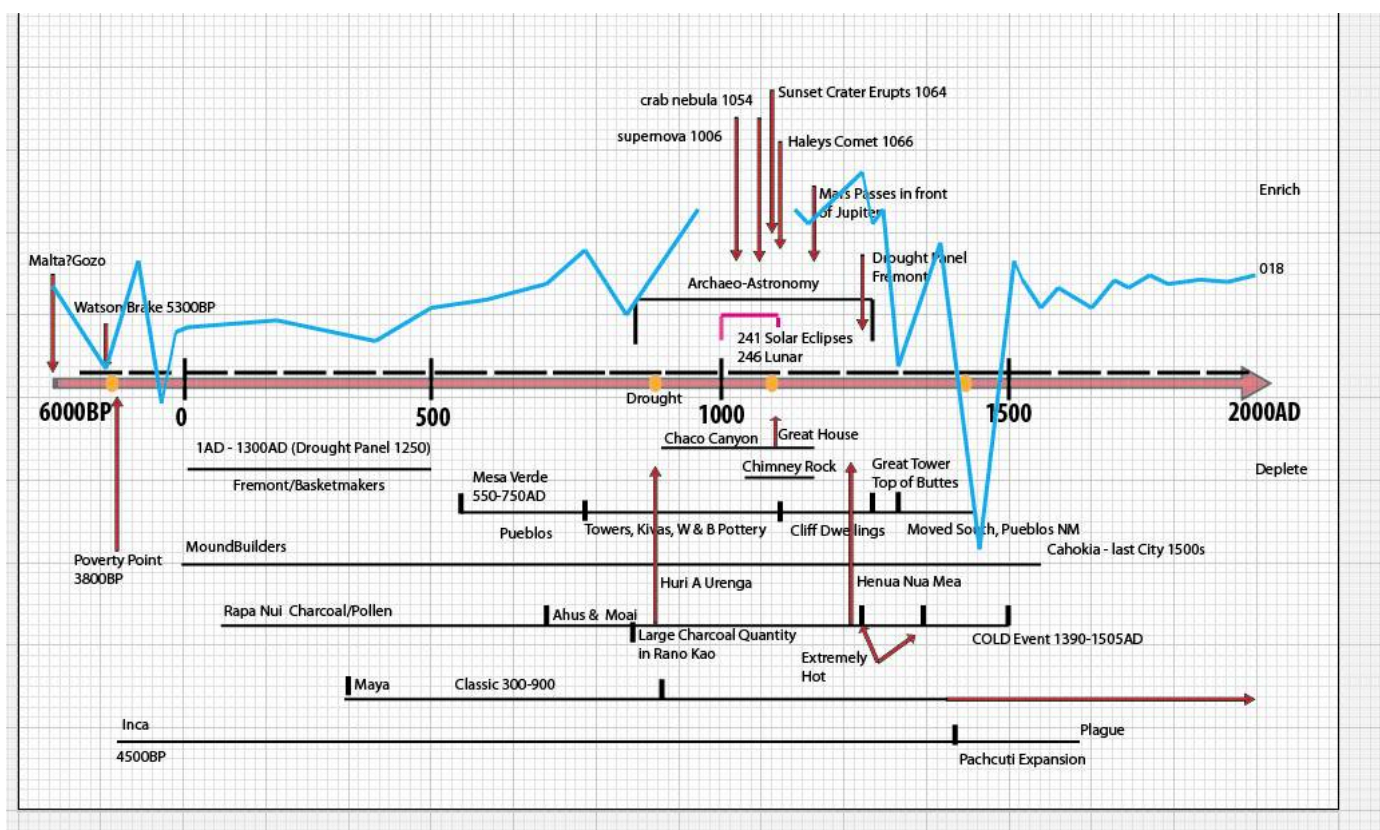

Figure 1 - Isotope analysis from Rano Kao with Celestial and Cultural Events over last 2,000 years 


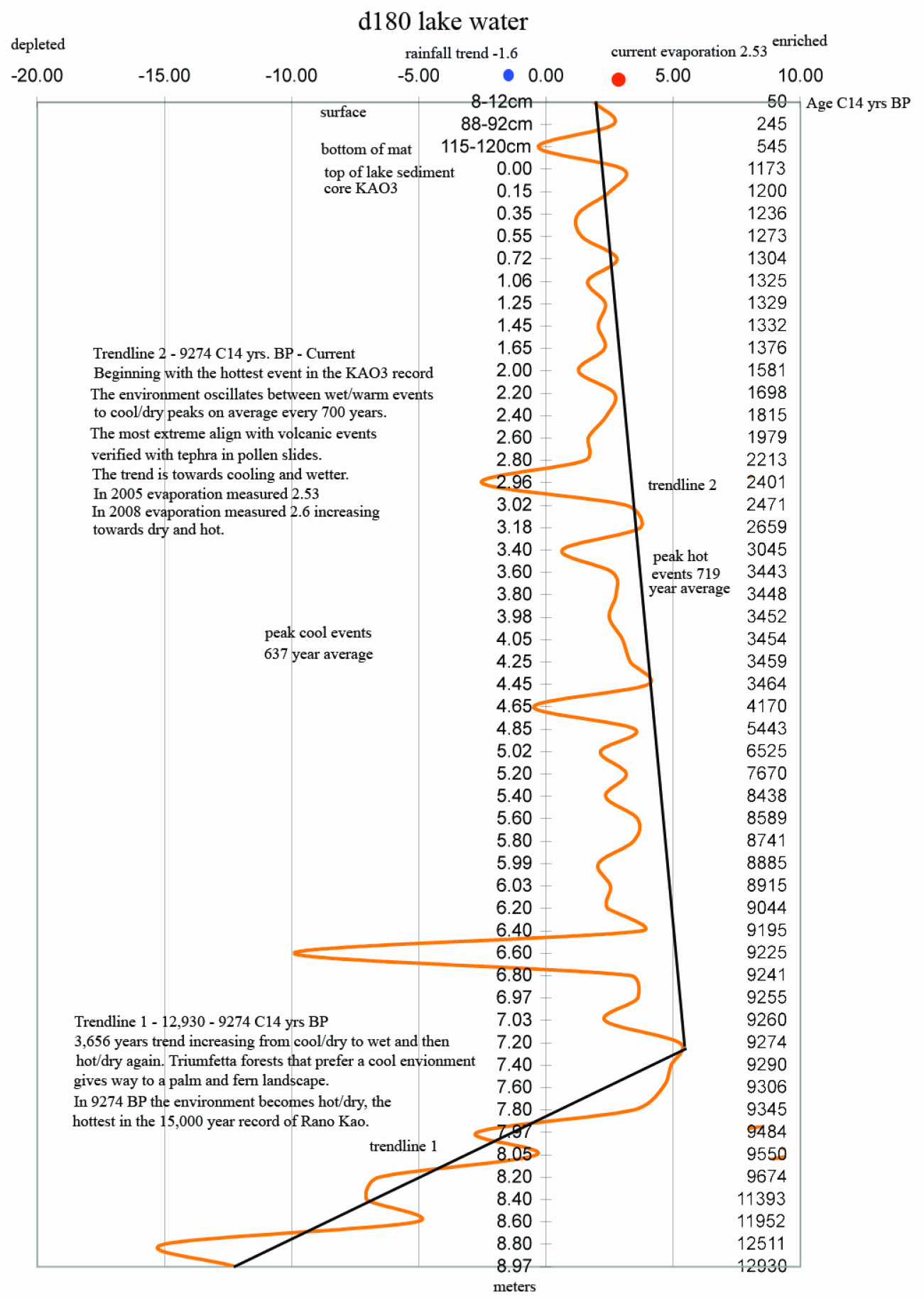

Fig 2 - 15,000 years of Isotope analysis with trendlines from Rano Kao 


\section{Mat 1 Oxygen Isotope Results Confirms 115 Year Cold/Dry Event}

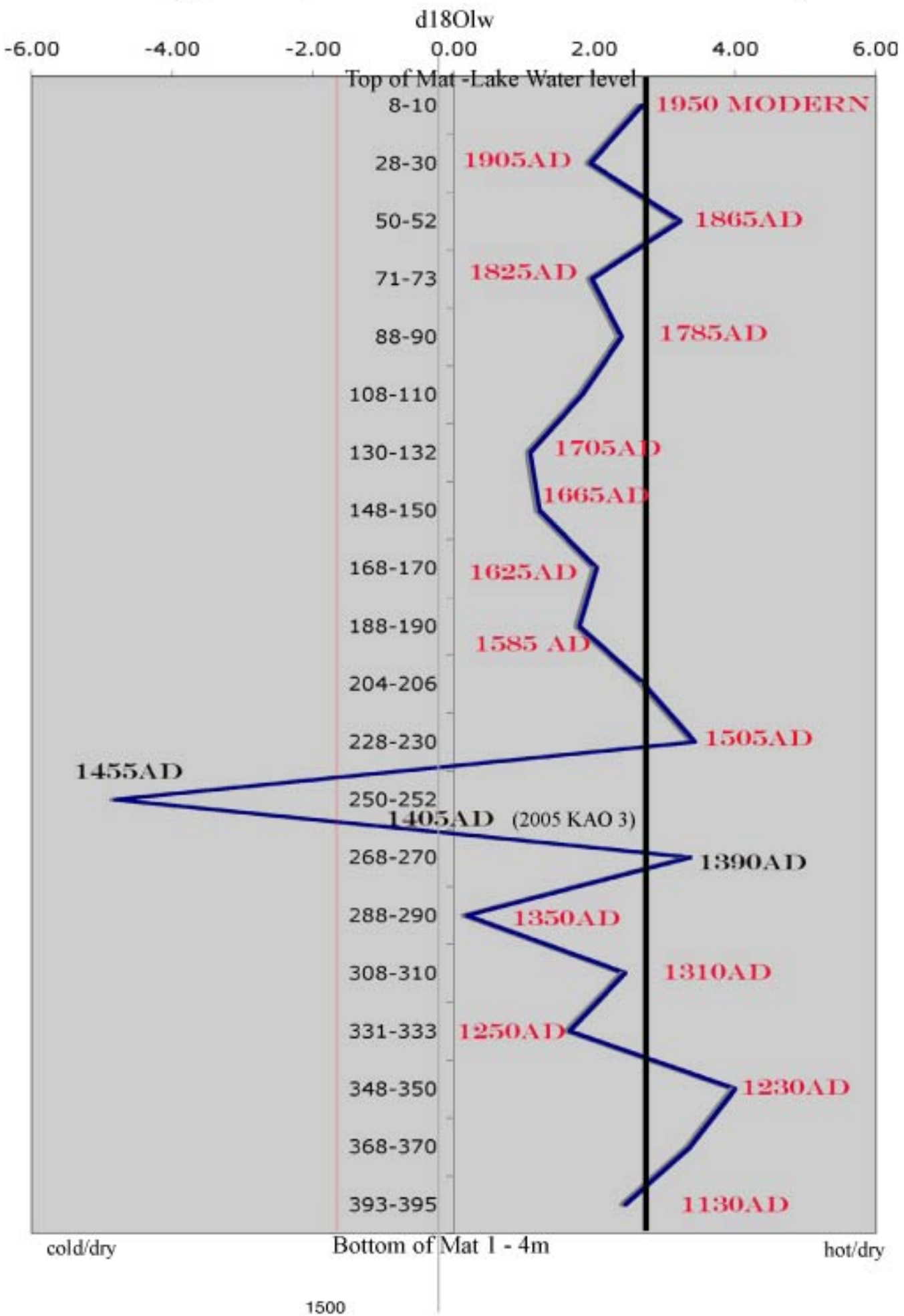

Fig 3 - Isotope analysis of floating mat of Rano Kao and last climate event peaking 1456AD 